\title{
Assembling a coalition of climate change narratives on UK climate action: a focus on the city, countryside, community and home
}

\author{
Candice Howarth $^{1}$ (D) $\cdot$ Laurie Parsons ${ }^{2}$ (ID
}

Received: 28 April 2020 / Accepted: 5 January 2021 / Published online: 19 January 2021

(C) The Author(s) 2021

\begin{abstract}
Perceptions of climate change and associated risks are complex and require greater consideration of the context in which behaviours are formed and changed. People tend to create their own stories of climate change providing an opportunity to capture personal experiences and frame solutions accordingly through narratives. Engagement with the issue can be further enhanced when using topics that resonate with individuals, especially through place attachments and local interests. Positioning climate change around communities, cities, homes and the countryside, for example, resonates with certain audiences as action at these scales provides useful narratives through which to engage audiences and increase positive associations with resilient and low-carbon futures. Nevertheless, we show how engagement with these narratives is complex and may overlap or contest in some cases. We present findings from thirty semi-structured interviews conducted with academic, policy and practitioner communities in the United Kingdom (UK) which explored what sub-themes could be utilised to engage audiences on climate change through narratives focused around cities, the countryside, communities and the home. We identify 10 sub-themes ranging from technological change (homes), connecting people (communities), alternative infrastructures (countryside) and positive visions of identity (cities). In search of a coherent coalition of diverse interests in shaping climate change action, we discuss two cross-cutting themes on technology and social norms which emerge strongly across each of the sub-themes.
\end{abstract}

Keywords Narratives $\cdot$ Climate action $\cdot$ Cities $\cdot$ Home $\cdot$ Countryside $\cdot$ Community

Candice Howarth

c.howarth@1se.ac.uk

1 Grantham Research Institute on Climate Change and the Environment, London School of Economics and Political Sciences, London, UK

2 Department of Geography, Royal Holloway, University of London, London, UK 


\section{Introduction}

The impacts of climate change are projected to worsen for countries like the UK with more climate extremes such as flooding and high temperatures (CCC 2017, 2019a, 2019b). The public may struggle to engage with, visualise or position themselves in the context of climate change as it is often seen as too distant both in time and geography for people to relate to, particularly in the UK, where impacts of climate change are relatively sparse. Salience to climate change can be more effectively achieved through the use of narratives (Howarth 2017) that enable behaviours, practices and systems occurring close to home, to more readily resonate with what climate change means at an individual level (in terms of experience of impacts and contribution to climate sources) as a 'narrative is assumed to play a central role in how individuals process information, communicate, and reason' (Jones et al. 2014: 10). We use 'narrative' to describe a type of discourse, according to Flottum and Gjerstad's definition of a narrative as being 'used to represent a specific kind of text/talk structure with a 'storyline' (in contrast to other structures such as argumentative, descriptive, and explicative) which can be realized through different genres such as fairy tale, novel, reportage' (2016:2). Consequently, constructing narratives can bring together diverse responses and harness personal experiences of climate change, and should thus resonate with a sense of place to increase salience to climate change and impacts. Indeed, "what people make of climate change, and what they do about it, are complex cultural matters, with a matrix of narratives, specific meanings emerging in and from particular times and places" (Daniels and Endfield 2009: 215).

Deeper engagement is required, going beyond information dissemination (which assumes audiences are empty vessels devoid of attitudes, beliefs, values and contexts which undoubtedly influence how information is received) in order to re-position attitudes or behaviours and enable better acceptance of the need for sustainable transitions. This is particularly true as "how we 'story' the environment determines how we understand and practice adaptation, how risks are defined, who is authorized as actors in the change debate, and the range of policy options considered" (Paschen and Ison 2014: 1083). However, perceptions of climate change and associated risks are complex in nature (Demski et al. 2014) and must consider the context in which behaviours are formed and changed, and how policies are formulated, by exploring values and preferences of people when they are dealing with unfamiliar issues (Lichtenstein and Slovic 2006). The way information is presented has a profound impact on how it is received, and engagement may increase if the message is directed at specific audiences who share similar values, beliefs and worldviews (Hine et al. 2014). Presenting mutually beneficial pathways towards low-carbon transitions in terms of health, well-being (Myers et al. 2012), energy security (Lockwood 2011) and using place attachment as a medium to connect with emotional and social meanings of climate change (Schweizer et al. 2013) can increase engagement on the issue, generating resonance not only with individuals but also wider social groups such as communities, cities, the home and the countryside.

Recognising this diversity of narratives is key to effective communication because climate change is not 'a salient, palpable issue' in itself (Lowe et al. 2006a, 2006b: 439), but impacts individuals with different interests in various ways. This is problematic for communication, but is by no means unique to the issue (Moezzi et al. 2017). What is crucial, therefore, is to articulate and coordinate these discrete interpretations, in order that their heterogeneity contributes to, rather than undermines an overall set of responses: a challenging task, but one with precedent in other areas of scientific communication, such as nuclear energy and (opposing) debates over intelligent design (Nisbet 2009). In both positive and negative ways, these 
examples highlight a number of lessons for climate change communication, demonstrating in particular the important role of narratives in coalescing diverse responses to an issue (Daniels and Endfield 2009), thereby providing the opportunity to harness personal experiences of climate change in the service of wider solutions (Hards 2012).

Thus, narratives have the potential to supersede one of the key challenges of climate change communication. Traditionally, climate change is 'an ugly story for media producers and consumers - difficult both to tell and to hear' (Smith 2014: 15) due in large part to the 'misalignment of scales' (Bushell et al. 2017: 42) between the problem and the potential for action. Yet as argued here, much of the difficulty in communicating climate change may be attributed to the preoccupation with engineering a single narrative to communicate a highly heterogenous problem. Rather than seeking a unified consensus, the most effective narratives provide 'interpretive schema' (Nisbet 2009: 45) rooted in 'culturally specific plots' (Paschen and Ison 2014: 1086) drawn from existing place attachments at multiple intersecting scales and can thereby 'transform ideas, attitudes and institutions and are thus essential to effectuate societal change' (van der Leeuw 2019). By examining effective climate change narratives in four key sites of climate change communication — cities, the countryside, communities and the home - this paper examines the confluences and contradictions of effective climate change communication. After outlining the conceptual and methodological approaches employed, it presents data on each effective climate change communication in each of these sites, before concluding with a discussion of the practical and conceptual lessons learned in each case.

\section{Narrating climate change in places}

\subsection{Climate change and the "narrative turn"}

Narratives connect people and give meaning to issues and events (Bushell et al. 2017); they provide a unique type of informal evidence, a different perspective and a way of connecting different stakeholders (Moezzi et al. 2017). They enable audiences to make sense of complex issues (Lejano et al. 2013) and are particularly effective at enhancing local understanding (Nash et al. 2019). Those focusing on change (i.e. past, present and future) are the missing link in climate governance, particularly at the local level where they act as an important integrator of climate information to social and cultural life (Krauß and Bremer 2020) enabling climate change to make more sense at that scale and capture local knowledge and expertise. They thus contribute to increased local knowledge, understanding and engagement with climate change, facilitate deeper connection to approaches to adapt to and mitigate climate impacts and enable integration and alignment with local life. These forms of communication enable a stronger connection to local climate change, which often cannot be achieved when presenting climate change as a global issue whose science and action worldwide are mismatched with action on the ground (Bremer et al. 2019). Narratives are highly effective when they move away from traditional mechanisms of communication of physical, technical and economic data, a process the public has become increasingly familiar, with no significant improvement in engagement on climate change (Howarth 2017). They are used to connect with, influence and engage audiences (Moezzi et al. 2017), and they help better integrate climate information on mitigation and adaptation where the local context is more effectively considered (Coulter et al. 2019).

Harnessing narratives is, however, complex. In the wake of the "narrative turn" across the social sciences 'as well as dissatisfaction with the dominance of physical, technical, and 
economic representations' (Moezzi et al. 2017: 1), the best means by which to harness and articulate climate change narratives has been the subject of considerable discussion in recent years. Hulme (2015) emphasises the rootedness of climate change narratives in culturally intertextual biblical narratives, arguing that 'the climate takes shape in cultures and can therefore be changed by cultures' (1), whilst Bushell et al. 2017 identify seven specific climate change narratives - from "every little helps" to the "the end of the world"- that frame public debate over the issue. Highlighting how these may lead not only to positive but also negative or defensive behavioural change (Bushell et al. (2017) and others (Menning 2018) call for a unifying narrative in order to supersede this disaggregation and provide clarity in climate change messaging. Nevertheless, this approach is contested in recent work (e.g. DevineWright and Batel 2017) of the value of more specifically targeted, place-based approaches.

Recognising, therefore, that 'there is no one general public' (Halperin and Walton 2018: 291), this paper seeks an approach capable of harnessing the diversity of existing narratives on climate change specifically, and place more generally. Like place-based opinions (DevineWright and Batel 2017), it is argued here, narratives of climate change operate at multiple intersecting scales (Paschen and Ison 2014) within wider social "metanarratives", as set out by Lyotard (1984). Narratives of climate change are therefore not only local but also inherently multi-scalar, the product of place attachment generated across linked, overlapping communities. These scales nest within one another quite comfortably in most cases and there is no tension in belonging to both.

Nevertheless, whilst recent literature has sought increasingly to understand the intersection of climate change narratives and place attachments (where place plays a 'significant and to some extent pivotal [role] [in] the production, reception, circulation, application and testing of climate change knowledge', Endfield and Morris 2012), the multi-scalar origins of place attachments have received less attention in the literature. Rather, 'existing studies of place attachments and place identities have taken a predominantly "local" focus (Devine-Wright 2013: 63), examining climate change narratives as they relate to a single focal context, rather than more complex placial arrangements. Consequently, 'research on attachments to more than one place (polylocal) and to places at different scales (polyscalar) has been neglected to date' (Devine-Wright 2013: 63). Seeking to bridge this gap, this paper examines place-based climate change narratives at multiple intersecting scales each framed by separate place-based narratives, but ultimately directed towards a complementary goal.

In doing so, we aim therefore to draw together two key areas of climate change scholarship. On the one hand, recent work on climate change narratives (as outlined above) and on the other, recent work towards a 'place-based science' (Boisselle 2016: 9) offering greater credence to locally articulated experiences of climate change. As is increasingly recognised, 'many places experience a persistent mismatch between predominantly science-based and technical framings of climatic risk on the one hand, and the place-based understandings of climate extremes and responses of people living in these places on the other' (Krauß and Bremer 2020: 1). One of the reasons for this is that place definition is complex and emically defined. No person belongs entirely to a single place, drawing instead upon a multiplicity of histories, experiences and identities in the construction of their worldview, nevertheless a place-based approach provides 'greater attention to the specificities of people's experience of climate and place' (Geoghegan and Leyson 2012). Within this context, 'narratives of change address the past, present and future of a specific place understood as a weather-world, adding a cultural dimension to climate change experienced as a succession of weather and seasons' (Krauß and Bremer 2020: 1). 
This paper therefore aims to resolve the tension between bottom-up and top-down analysis of climate change (Conway et al. 2019) and in doing so, provide a platform for more effective governance and policy. Directed towards the identification of a complementary coalition of such narratives, this research explores climate change narratives as they relate to four key sites of place attachment: homes, communities, cities and the countryside. Moreover, not only are these sites associated with strong place-based narratives in their own right but also each offers a distinct set of climate change related behaviours. We discuss these themes in more depth in the following sub-section.

\subsection{Narrating climate change in the city, countryside, community and home}

Throughout the twentieth century ebbs and flows of public interest in environmental and climatic topics have been a persistent characteristic of their narration. Certain scholars (e.g. Downs 1972) have even argued this to be an inherent characteristic of a topic which lacks tangible imagery and thus cannot compete with more immediately newsworthy alternatives. Yet more recent scholarship has adopted a constructivist approach, emphasising the framing of climate change narratives as a key component in their reception. In particular, following the decline in public engagement with the issue of climate change from 2009 onwards, the "Gore Narrative" which famously claimed that 'the science is finished' (Smith 2014: 15) on climate change has been criticised for its 'condescending' character (Nisbet 2009: 44).

Not only are single holistic and tangible truths not always achievable within the limited and interested constraints of human perception (Moezzi et al. 2017) but also the diversity of interests characteristic of climate change stakeholders renders any such narrative more effective in some cases than others. For the purposes of this paper, four such intersecting placescities, the countryside, communities and the home-have been identified as key to climate change communication. These are by no means intended as exhaustive or firm categories. Indeed, as noted above, the very notion of unitary places is problematised by the complex histories and identities that make them up. Instead, these four categories are offered as emically defined and heuristic categories. To contextualise the analysis presented, we define these in Table 1; however, respondents were not offered definitions, but encouraged to self-define on their own terms. The narratives identified within each category therefore relate to variegated but mutually intelligible concepts, around which a complex set of meanings coalesce.

Cities play a complex role both in climate policy and messaging. They are where the majority of people around the world now live and work, where significant contributions to climate change are made. They are likely to be significantly impacted by climate change in a

Table 1 Broad definitions (adapted from Rogers et al. 2013)

\begin{tabular}{ll}
\hline $\begin{array}{l}\text { Place } \\
\text { category }\end{array}$ & Definition \\
\hline City & $\begin{array}{r}\text { A cluster of people, businesses and governmental institutions with activities normally connected to } \\
\text { international flows of information, goods, money and people. }\end{array}$ \\
Countryside & $\begin{array}{r}\text { A rural landscape with limited urbanization, small populations with limited development and } \\
\text { economic activity and where settlements are contained to small towns or villages. }\end{array}$ \\
Community & $\begin{array}{r}\text { A group of people, place-based or virtual, with a common set of customs or circumstances and } \\
\text { centred on common interests and/or a locale. }\end{array}$ \\
Bome & $\begin{array}{l}\text { Both real and imagined and generally a place of residence associated with intimacy and personal } \\
\text { autonomy where materialist consumption and state regulation occurs. }\end{array}$ \\
\hline
\end{tabular}


number of ways, from direct impacts from flooding and high temperatures to indirect impacts on citizen's health and well-being (HPA 2012) calling for enhanced resilience and adaptation measures. Cities are therefore an important context through which to achieve a resilient, lowcarbon future. Whilst cities are 'innovation hubs where different actors have the capacity to develop fruitful, participatory contexts aimed at stimulating sustainability transitions' (Olazabal and Pascual 2015: 343), they can also act to distance and disengage citizens from their need as individuals to adopt sustainable behaviours. Given this tendency to 'distance climate change from their personal realm' (Scannell and Gifford 2013: 62), the diversity inherent in cities makes achieving effective climate change narratives especially challenging. In order to 'reduce the gap between climate impacts and personal concerns' (Scannell and Gifford 2013: 62), therefore, an effective urban narrative must be aware of and respond to the personal concerns of multiple different types of stakeholder.

The countryside is often perceived as a key site of vulnerability to climate change, encompassing a range of intersecting themes such as agriculture and farming, food and diet, forestry and land use. Arguments justifying the economic value of ecosystems and biodiversity have been a topic of much discussion for decades: providing the value of these services is a powerful way to communicate the importance of conservation and effective land use management to wider audiences (Atkinson et al. 2012). In addition, the countryside provides an opportunity for renewable energy infrastructure with potential technologies (DECC 2011) that could generate 30-45\% of all energy that is consumed in the UK by 2030 (CCC 2015). The impact of these initiatives on the countryside and to the UK's plans to meet carbon budgets could be significant, with implications for public engagement. Moreover, as a site likely to be affected in a more direct manner than urban areas, the countryside offers the potential for more direct, or linear "cause and effect" narratives to be effective in climate change communication. Nevertheless, efforts in this regard have long been hampered by scalar disjuncture - place attachment to the local and disconnection from the global (Devine-Wright and Batel 2017) - and NIMBYism rooted in strong local place attachments (Devine-Wright, 2009). In order to succeed, successful rural climate change narratives must therefore specifically address these challenges.

Communities provide space for cooperation around sustainability issues, as well as being threatened by the impacts of climate change. Despite being challenging to define (Aiken 2012), the rhetoric of community in the UK has been used frequently throughout public policy and campaigns for action on climate change as it helps to gain buy-in from local residents, provide scale and reflect grassroots activity (Aiken 2012). Communities provide local processes for the flow of trusted information (Middlemiss and Parrish 2010), active involvement and support locally (Heiskanen et al. 2010), ultimately furthering the development and/or enhancement of local identities particularly when considering the carbon context (Mulugetta et al. 2010). Thus, how a community "stories" its past experiences and actions ultimately determines how it understands and practices future adaptation' (Paschen and Ison 2014: 1084). Communities provide 'a shared framework of meaning to unify and coordinate what different actors say about what needs to be done to mitigate climate change' (Bushell et al. 2017: 41). Moreover in framing problems on a larger than individual scale, they have the potential to address a sense of helplessness that can sometimes inhibit individual behaviour change. Exploring how best to leverage the 'place, place-attachment, and connectedness' which often inheres in communities is therefore an especially 'important area of future research' (Galway 2019: 84).

The home is one of the most powerful loci of place attachment, and has a key role to play in climate change messaging. Homes are where people have created their own personal environments and hence form part of their identities, but also where behaviours are likely to affect 
carbon emissions (e.g. the residential sector contributed $18 \%$ of the UK's greenhouse gas emissions in 2018, BEIS 2019) and climate impacts may put private lives at risk (Jarnkvist 2019). The home therefore presents significant opportunities for reducing emissions; however, individuals need to become better engaged with the 'why' and 'how' they can change, in order to make drastic changes in behaviours and lifestyles (Poortinga et al. 2012). There is moreover a broad assumption that the implementation of technologies, such as smart metering, in the home can act as a positive intervention on the behaviour of home owners and consumers of domestic energy, known as, the 'techno-rational paradigm' (Guy and Shove 2000). However, this needs to be mindful of perceived threats and opportunities in these initiatives, where issues around autonomy, privacy and mistrust of suppliers drive adoption of these practices (Buchanan et al. 2016). As such, taking a holistic approach to the home will better enable people to adopt more sustainable practices and lower their carbon output (Balta-Ozkan et al. 2013).

\section{Approach}

Recent scholarship on climate communication has largely left behind the assumption that simply "informing the public" of the facts of science will meaningfully alter the perceptions of either policymakers or citizens (Nisbet 2009: 42). Instead, there is a growing recognition that communicating the issue effectively involves 'a negotiation of meaning' (Nisbet 2009: 42) sensitive to endogenous, place-based narratives of environmental and climate change (Halperin and Walton 2018). This work has demonstrated how narratives that are personally attuned to individuals' and communities' senses of place are likely to be more successful in communicating climate change messages than unifying narratives, which seek to draw a straight line from 'apocalyptic scenarios to low-energy lightbulbs' (Smith 2014: 5).

This paper aims to draw together expert opinion on effective narratives associated with four key sites of climate change messaging, in order to highlight both the differences in what constitutes an effective narrative in each site, and the potential confluences and mutual engagements between them. In doing so, the paper has three specific goals: to (i) provide a repository of effective climate communication narratives in cities, the countryside, communities and the home; (ii) demonstrate the need to tailor climate change messaging to integrate and cohere with existing narratives of place; (iii) demonstrate that, rather than attempting to establish a unifying message, the most effective climate change messaging must appeal to an interlinked coalition of interests by utilising multiple narratives in combination.

Thirty semi-structured interviews were carried out with $10 \mathrm{UK}$ academics (labelled as 'aca'), 10 policymakers ('pol') and 10 practitioners ('pract'). Interviewees were selected based on their knowledge and experience of climate policy, emissions reductions initiatives and constructive mechanisms to engage the public. Interviewees covered a range of backgrounds and expertise with specialisms including climate science, UK carbon budgets, public engagement, behavioural science and climate policy, with varying levels of seniority to ensure a representative sample. Organisations represented by interviewees included 'Aca': universities; 'Pol': UK local and national government departments; and 'Pract': city-based climate initiatives/networks (e.g. such as community-led, national/international focus or working alongside local authorities), consultancies and climate media/communications agencies.

Interviewees were asked questions around two themes (Table 2). Each interview lasted 30$60 \mathrm{~min}$, with questions piloted beforehand and was audio-recorded and data was transcribed 
and analysed using discourse analysis via NVivo. Final interview transcripts were sent to interviewees for review and quality assurance and responses were kept confidential and made anonymous to protect personal privacy and encourage frank discussions. A thematic discourse analysis was conducted on the data to draw out prominent themes. The sample size $(n=30)$ and UK representation of the participants may be seen as a limitation to the study and we acknowledge that the values, biases and agendas of the academics, policymakers and practitioners interviewed may influence their responses. Interviewees spoke in their professional capacity and were not encouraged to speak on behalf of ordinary people. We encourage further research on the topic with larger sample sizes and representation from different geographical and sectorial populations. Nonetheless, data from these interviews provide valuable insights into how to frame climate change around homes, cities, countryside and community.

\section{Findings and discussion}

We explore the effectiveness of climate change narratives in four contexts: cities, the countryside, communities and the home. By examining the confluences and contradictions of effective climate change communication in multiple places and at multiple scales, the intention is both to demonstrate the shortcomings of unifying climate change messaging and the potential of a more multi-stranded approach, which achieves impact through a diverse array of effective messaging.

\subsection{Cities}

As the analysis here shows, there is popular support for the idea that city-based sustainable and efficient transport and energy systems will lead to cleaner air and increased levels of wellbeing, mainly through higher rates of walking and cycling and reduced congestion and air pollution and noise pollution. In narrative terms, innovation and prosperity and personal identity and pride similarly were suggested as appealing with particular recognition for investment opportunities that would emerge. Whilst suggestions are made to avoid highlighting issues of social inequality in the city, this provides the opportunity to draw on and intersect with the home and communities narratives, in relation to which a clear narrative consensus emerges across interviewees around the benefits to quality of life of a low-carbon future. There

Table 2 Interview discussion points

\begin{tabular}{ll}
\hline Theme & Discussion points \\
\hline $\begin{array}{l}\text { Theme 1: exploring the construction of narratives at } \\
\text { the level of cities, countryside, communities and } \\
\text { homes }\end{array}$ & $\begin{array}{l}\text { (i) Positioning themes of low-carbon and resilient fu- } \\
\text { tures in these narratives } \\
\text { (ii) Key elements of a narrative needed to enable } \\
\text { audiences to see a low-carbon and resilient future as } \\
\text { desirable. }\end{array}$ \\
$\begin{array}{ll}\text { Theme 2: exploring the impact of these narratives in } \\
\text { empowering audiences }\end{array}$ & $\begin{array}{l}\text { (i) How people will respond to the changes needed in a } \\
\text { low-carbon and resilient future, }\end{array}$ \\
$\begin{array}{l}\text { (ii) Main opportunities that emerge from a low-carbon } \\
\text { and resilient future }\end{array}$ \\
$\begin{array}{l}\text { (iii) How these narratives can enable audiences to feel } \\
\text { more empowered to respond to changes needed to } \\
\text { adapt to the impacts of climate change at the level of } \\
\text { cities, countryside, communities and homes. }\end{array}$ \\
\hline
\end{tabular}


are two strands of thinking about this: (i) a clear emphasis on the benefits of green spaces and recreational areas to help tackle climate change as these can replace car-heavy roads, and (ii) relying on opportunities for resilience building to extreme and hostile weather. The existence of both these strands is especially important because, in contrast to the assumption that 'those exposed to a local framing were more likely to take personal-scale adaptation actions' (Halperin and Walton 2018: 291), it demonstrates the city frame's ability to encourage support for policy-scale adaptations also. Moreover, it supports the contention that 'intangible largescale effects of climate change which are so often reported to the public become "real" only when put in more local terms' (Lowe et al. 2006a, 2006b).

\subsubsection{Vision for a positive city lifestyle}

Cities are often viewed as fast-paced, noisy, polluted and stressful to reside in or visit, "that they're clogged with cars, the air's un-breathable, and so I guess if you can frame a low carbon future as one where people find it easier to move around, the air is actually breathable..." (Pol4). A climate-resilient and low-carbon future provides an opportunity to re-position the city as an environment which thrives, is pleasant and innovative. Rather than focusing on the negative attributes of a city, "making cities more liveable places, so with fewer cars around, fewer polluting vehicles, more electric vehicles, more walking and sitting opportunities. The notion of the pleasant city starts to become a bit more meaningful." (Pract9).

Whilst better-integrated transport systems provide services to those most in need, not all enjoy using this mode, and electric cars are viewed as an opportunity to ensure mobility independence and reduce air pollution and congestion. However, slow and/or limited uptake of this technology is associated with cost limitations and barriers to adoption of new technologies.

Buying an electric vehicle, again, is one of those things that costs more up front (...). It's just a better technology than the one we have. So I think once you get over a certain hurdle and more people see more people they know who have this technology and are happy with it, then that can be overcome (Pol2)

As city-driven innovation and advances in technology increase, a low-carbon approach to this could reduce social inequality and increase social cohesion. A selection of interviewees work directly with individuals who may be prone to health and social well-being issues: “...there is a deep amount of loneliness in big cities and big urban environments. (...) I kind of think that in a greener society, the more communally driven society, this will be one of the benefits, one of the pluses, of such a society that loneliness particularly in an urban environment, would be reduced I would hope" (Pract8). A low-carbon, climate-resilient future would result in increased community cohesiveness (from low-carbon initiatives) and provide significant social and well-being benefits within cities.

\subsubsection{Open, green city development}

A low-carbon agenda engenders the sense of a 'smart' and safe city. Similarly, cities are known for driving innovation, and a sustainability agenda can create space for innovation in energy, transport and food. This merges with other messaging around energy and homes where, "for cities it's something about connected, efficient and prosperous cities. (...) and more connectivity in a city actually leads to more prosperous place" (Pol6), bringing people together through community and 
home efficiencies. The connection is made between a low-carbon future and resilient cities with acceptance that they will demonstrate pioneering and innovative technology to reduce carbon emissions whilst having a strong and resilient infrastructure to withstand extreme weather.

I think in cities where heat stress and surface water flooding will be major challenges I think there's that element that whilst low carbon will make our lives better, climate change is continuing to happen and making our lives more challenging. (Pract7)

Similarly, interviewees highlight how a low-carbon future would be seen as desirable and positive if there were more green and recreational spaces within the city. Such a low-carbon future could be achieved through more efficient transport for example and green spaces would offer more opportunities for walking and cycling, with added benefits to health, well-being and reduced air pollution levels.

I think it's important not to see cities as being somewhere apart from nature. (...) I think there's a big role for urban green space. A more pleasant living environment, and that encourages people to take exercise more. (Pract5)

You know segregated cycle ways, all these things kind of make a very tangible difference to how you perceive somewhere and the smell, the look, the feel of a place is so much better if you start to reduce the amount of carbon intensity that is going on there (Pract9)

\subsection{Countryside}

Our analysis shows that the countryside narrative is dominated by narrative contestation over energy infrastructures and natural heritage. Consequently, certain energy solutions are preferred over others: making low-carbon transport more suitable for all, local energy networks and energy independence are - in the interests of preserving the natural beauty of the countrysidepreferred to national infrastructures. In particular, onshore wind is considered the most obstructive form of low-carbon technology and is subject to 'NIMBYism'. Nevertheless, the countryside engenders a strong narrative around maintaining and preserving the landscape and the implementation of more or better alternatives to existing green technologies relevant for day to day activities in rural environments such as transport and infrastructure, energy, land use and agriculture. As such, place attachment, 'the formation of emotional and cognitive bonds with a particular place' (Scannell and Gifford 2013: 66), plays a role both in shaping attitudes towards particular low-carbon policies and encouraging uptake of those policies once established. The countryside's strong local focus means that the most effective climate change narratives in the countryside emphasise the protection of natural heritage and local economic benefits, rather than global or longer-term threats.

\subsubsection{The natural environment as heritage}

Constructing narratives around preserving the countryside may be an appealing way to engage those who are perceived to have "some knowledge, some sense, of the importance of the countryside, and 
the importance of tradition and valuing our natural heritage" (Prac5). Some individuals may oppose anything that can negatively impact the countryside providing a useful opportunity through which to frame the co-benefits of low-carbon initiatives: “.. for people who care about the countryside, anything that disrupts the local countryside, even though it's better in terms of the bigger environment, will be a problem. So the developers of new energy technology should be trying to minimize that if they want to get these people on-board." (Acal).

The preservation of the natural environment is important, with an emphasis on cleaner air and environment, having a "collective responsibility for the land" (Pract5) and "not managing for quick profit for the next few years, but thinking about what you're going to hand on to your ... to future generations, to your children" (Pract5). This should encapsulate less intense use and management of rural land, as well as shifts to more sustainable agricultural practices in order to ensure "[the countryside] should continue to be something that has multiple benefits, and part of that is about using the land efficiently." (Pract5). With low-carbon technologies considered an intrusion on natural landscapes this further exacerbates resistance to change. A recurring theme is that of Britain as clean and pleasant land and a core desire to preserve the beauty of the countryside as a feature of British culture. Situating low-carbon technologies in the countryside calls for a re-framing of terminology, often tainted through exhaustive debate on the issue and a politicisation of the term.

There is some knowledge, some sense, of the importance of the countryside, and the importance of tradition and valuing our natural heritage. (Pract5)

(...) any conservation message that focuses on keeping the English countryside as beautiful as people now believe it is, that will be important for that framing (Aca1).

\subsubsection{Co-benefits and overcoming isolation}

Highlighting the co-benefits of climate solutions (whilst not using low carbon as a benefit) and applicability to the UK countryside may prove most effective, particularly when highlighting "benefit of employment, taking people out of the welfare state, re-skilling people, driving a manufacturing skills-led economy, then some of the areas like carbon capture and storage are areas where you could plug the opportunity." (Pol2).

I guess if you can explain that coal is no longer the cheapest, onshore wind is the cheapest and that actually if the country wanted to increase its energy security without massively increasing the bills, onshore wind would be the way to do it. (Pol4)

Effectively engaging people around a countryside narrative by providing solutions to climate change that are perceived as efficient and suitable for daily challenges of countryside living would resonate. The rising cost of public transport and a lack of effective alternatives, such as better infrastructure are seen as slowing a process to low-carbon transitions in the countryside and rural communities. This is more likely to be linked to energy and transport: "they're concerned with issues around fuel cost, transport, use of energy in farming and that kind of thing" (Prac2). 
Transport is a big issue for the countryside, how people can get around (...).The extent to which people are served by public transport, again, investing more in public transport so it's more convenient for rural communities rather than them all having to own private cars is important shift. (Pract7)

Independence, self-sufficiency and security emerge as important in responding to climate change at the countryside scale, with an emphasis on highlighting the wider co-benefits that emerge from climate solutions that are gained through localised control of resources: "it could give them a kind of greater sense of independence or security if that's something that was going to appeal to them (...), certainly in rural areas it's not something that people are that keen on so actually having a kind of localized energy network or kind of, resource could be something that's seen as very positive" (Pol1). There is resistance towards accepting physical infrastructure to support and generate energy needs of local communities. There is nonetheless a greater sense of autonomy and the idea of self-producing one's own energy within the local countryside can reduce perceived barriers towards acceptance of low-carbon technology infrastructure in the countryside.

\subsection{Communities}

Caution is needed for a narrative around 'communities' as interviewees highlighted the dual interpretation a 'community' frame can infer. On the one hand, this may be a positive, inclusive, relationship-strengthening 'hub' which enables fruitful and localised initiatives to come to fruition. On the other, however, it has an association with terms such as 'community centre' which can engender strong negative emotions and feelings of disassociation and distancing. Thus, as is now increasingly recognised, community is not a simple or homogeneous category, but a multi-scalar set of place attachments (Devine-Wright and Batel 2017). Community-focused narratives must account for this complexity by recognising that community narratives contest and overlap. Local economic benefits may be enjoyed to a greater extent by some more than others, for example, whereas the most effective narratives will speak to the benefit of multiple local groupings. As with a countryside narrative, therefore, making a community-focused case for a low-carbon resilient future will require emphasis on local economic gains, with specific aspects of this to include: creation of new businesses, employment opportunities, re-skilling opportunities, connecting people, staycation and place attachment, support for local businesses and local expertise retention, potential for bottom-up solutions to major costly national problems, improving peoples' well-being and reducing economic pressure on health and social care services.

\subsubsection{Increasing connectivity}

Community schemes or businesses provide important opportunities upon which low-carbon initiatives are based, such as increasing local employment and re-skilling people locally whilst increasing voluntary experience and apprenticeship opportunities. Similarly, this builds connections amongst community members, where, for example, "we spent a lot of time teaching people how to grow their own food how to prepare their own food and so on" (Pract8), and this raises awareness of the added value of increasing the availability and access to local services which can enable people to feel more connected (e.g. through community based initiatives 
such as the food-related example provided by Pract8) and further reduce negative social issues such as feelings of isolation. This is not specific to communities and is also applicable across the city, countryside and home contexts. The role of social norms and peer influence further encourages people within close communities to demonstrate an interest in low-carbon initiatives and demonstrate leadership themselves: "because the best person to persuade you to put solar panels on your roof is your neighbour. They have full agency of being truly, truly local." (Pract1).

As members of some local communities actively engage in low-carbon community schemes, there seems to be the development of community spirit (a feeling of involvement in and concern for one's local community) or a "collaborative framework as a society" (Aca3), which engenders support for local businesses, helps create local solutions to global problems and can potentially be harnessed to tackle major challenges.

I think everyone has started to realize that a top-down approach is not the only way and that a bottom-up approach has to be basically applied. (...) I think that the citizens will have to be ready to, you know, they have to be proactive, they have to build flood defences around their home. (...) So that I think will have a positive impact at the end so I'm confident that communities will find a way of adapting even if it does mean that, uh, some communities will have [to] change (Aca3).

We need to sort of show people how effective it is if community adopts a community energy scheme and the youngsters within the community start building these panels and putting them on the on the roof. We need to make these things a source of pride for a community (Pract8)

\subsubsection{Addressing community scepticism}

The issue of what a community means to different people came up in a number of interviews. Interviewees highlighted terminology such as 'community' was an ineffective way to engage with people as for some "Community means community centre. Where poor people go." (Pract10). Using terms such as 'local', 'neighbourhood', 'connection' and 'local pride' would better reflect a sense of shared responsibility and increased local relationships. However, some audiences do not identify with the concept of community, instead seeing it as representing antiindividualism and often linked to perceptions of low or no wealth: "They don't see communities as something they're very interested in, they're interested in individual, self-interest and freedom." (Aca1).

Some audiences demonstrate individualistic tendencies and addressing this head on may lead to a shift to a collective and balanced (social, economic and environmental sustainability) frame. This can encapsulate the need for combined behaviour change approaches, without imposing a community-focus with a recognition of the broader low-carbon, societal and economic benefits of implementing these: "I personally think you can't really get meaningful behaviour change from a bunch of people who don't understand why the behaviour change is needed. (...) So I think an educated population is going to be something for the future and a population that's more engaged and bothered about you know, getting involved in their local communities, projects, and schemes." (Pract8). Increasing that engagement to those who are 
less inclined to respond favourably to low-carbon initiatives will require getting "across the diverse experiences that people have ... So that you're actually connecting with people in terms of what they already think of as their community" (Aca4).

\subsection{Homes}

The home presents a range of potential foci for a narrative: enabling individual choice, independence and control, demonstrating the low-carbon and sustainability benefits of the low-carbon agenda, affordability, well-being and broader benefits, technology innovation and development, behaviour change. Affordability emerges strongly as people maintain a desire to keep their homes comfortable and warm with well-being and broader benefits of energy efficiency holding particular importance to householders. In addition, technology innovation and development are recognised as necessary mechanisms to ensure low-carbon transitions. Nevertheless, the home is viewed as one's sanctuary, where individuals build and protect their identities, so the importance of preserving individual choice and comfort within the home override the need for reductions in emissions. A successful narrative of a low-carbon resilient future must therefore align with householder preferences and may be designed to be absorbed into a home's fabric, with minimal visibility. As with the community narrative, it is also important to avoid viewing homes as either internally or externally homogeneous. Rather, both between and within homes, 'different intersections of class, gender, age, and place shape different ways of positioning in relation to risk, by describing oneself as more or less aware of and exposed to climate risks' (Jarnkvist 2019: 1). As a powerful and evocative object of place attachment, long used in the construction of climate narratives centred on present generations' legacy to future ones, effective use of the home in climate change messaging must recognise and appeal to household diversity. Classed and gendered constructions frame the management of climate change risk in relation to different aspects of the home - technical "know how", as opposed to theoretical knowledge, for example (Jarnkvist 2019) — whilst age similarly presents a different set of imperatives: younger people are more global and longer term in outlook, in many cases (Jarnkvist 2019). Speaking to each of these narratives, rather than only one, has the potential to greatly enhance the power of climate change messaging centred on the home.

\subsubsection{Removing barriers to technology uptake}

Automation of energy systems is often thought of when considering low-carbon homes, and consumers have a preference towards remaining in control of their energy consumption. With increased technological innovation and plans to create 'smart' homes, individuals are more likely to engage positively with such innovation if overall control and choice remains with the user and enables greater empowerment and financial savings: "I think introducing people to what they can do in their own homes. So these clever meters for example, you know that can measure how much you're consuming in energy (...) if people understand that they can basically decrease their consumption say, they'll be very positive to it" (Aca3).

Behaviour change and choice architecture are required nonetheless to enable sustained adoption of low-carbon practices. Ultimately people want "comfortable houses that are cheap to run" (Prac5), "less expensive to live in" (Pract4), with a "lower cost to operate" (Aca3). Transparency of what is expected from consumers when it comes to their energy usage, 'so then it becomes normalized' (Pract3) may further encourage sustainable behaviour if consumers are able to understand how their behaviour contributes to a reduction in their household 
emissions. Whilst energy generation and independence of consumption are strong appealing narratives that emerge from the interviewees, innovation and technology advancement, aligned with societal needs for a low-carbon future also emerge where change can be viewed as beneficial and desirable. The sense of identity, pride and ownership is strong when considering people's homes and the significance of a home to them and their family (i.e. comfort, sanctuary). Maintaining this is therefore important in increasing engagement on climate change and a low-carbon future, these characteristics of homes and transitions to sustainability must be incorporated into broader narratives.

for the home, energy's quite a difficult concept for people to engage with. (...) as soon as he [my dad] got his solar panels on his garage he's out there every day reading about how much energy he's got. He now knows how much energy the kettle uses, you know, it starts to set those kinds of things into context. I think so for him he's able to set the energy he uses in the house in the context of what he produces. (Pol4)

Whilst resistance emerges quite strongly, there is acceptance of the need for change for a lowcarbon future with preference for these changes to be absorbed into the 'fabric' of one's home, maintaining individuals' creative freedom to design their own personal environments: "Well I imagine they will look pretty similar to now, cause people aren't going to want something that looks dramatically different I don't think.” (Pol6).

\subsubsection{Positive engagement with climate action}

Sustainable societies drive innovation and technology, creating employment and investment opportunities, and can provide energy security and be cost effective to households. Whilst leading a narrative with a 'low carbon', 'greenhouse gas emissions', 'transition' or 'mitigation' focus was generally not advised by interviewees, providing information on the benefits of changes needed to adapt to a changing climate would enable householders to make linkages between their individual practices and broader national climate action. For example, increasing motivation to adopt sustainable behaviours by framing this as a good investment opportunity would increase 'feel good' feelings, which can be further enhanced by providing additional information about the co-benefits and positive impacts their change has had: "I think people in general will be using more energy, will be more energy efficient, so in addition to having more control, we'll live in, hopefully better insulated homes, which will require less energy to heat and keep cool in the summer. Whilst low carbon will make our lives better climate change is continuing to happen and making our lives more challenging" (Pract7).

Whilst technology will be relied upon heavily to help deliver changes that are required under a changing climate, behaviour changes will also be required to ensure adoption of new technologies and lifestyle choices compatible with these. Peer influence and social norms are important motivators and reinforcers of sustained changes particularly where technologies may be perceived as visually intrusive: "There's almost a kind of pride thing that you would want to show off, almost, to your neighbours, that you don't waste energy, and you generate your own energy (...)" (Pract6). Low-carbon factors may not be motivating behaviour or encouraging the adoption of new technologies, however the desire to be an 'early adopter' motivation and "to be seen to be the first to have certain things" (Pol1), and financial savings attributed to the resulting low-carbon benefits, may further entice individuals to engage favourably: "if someone wants to see it as a status symbol and they're using that electric vehicle for that purpose as 
opposed to an environmental or economic one then so be it, I think it's ultimately still delivering the same wins" (Pol1).

\section{Conclusions}

What makes climate change a 'super wicked problem' (Bushell et al. 2017:40) is not only the technical difficulty of ameliorating it but also the range of interests involved in persuading coordinated action to go ahead. The conundrum facing climate change as Smith (2014: 5) summarises is that it is 'understood to be urgent and important, and at the same time is widely seen as boring, difficult and confusing. It poses a global risk, and yet is highly divisive. It represents a defining challenge for our age, and yet it is one that many people choose to ignore and some, even, to deny'. An issue that tends to be presented as unified, albeit highly complex in policy circles, manifests in the public sphere as a broad and often antithetical gestalt of opinion, rooted in strongly held, multi-scalar place attachments, and contested narratives of value.

In order to effect meaningful change in public attitudes towards climate change, 'the structure in which information is embedded is of great consequence for eliciting proenvironmental behavior' (Morris et al. 2019: 31), therefore, it is necessary to observe the intersection of narratives across and between places. Place attachment is a powerful tool in climate change messaging and is constructed in multiple linked places and at multiple scales (Devine-Wright and Batel 2017; Halperin and Walton 2018). Moreover, it is in many respects subjective in nature. Spatially rooted framings, such as rural and urban, are necessary but not sufficient dimensions of climate change messaging. Placial framings, such as community and home, cross-cut these frames, meaning that climate change communication must take account of variety and contestation in the receipt of messages. No "single, static "story" repeated verbatim' (Bushell et al. 2017: 41) is able to supersede this variety. Consequently, rather than seeking to construct a unifying narrative, climate change communication will be better served by coordinating a coalition of interests, via a linked series of narratives capable of appealing to groups that may have little in common with one another.

Articulating climate change narratives in an effective way presents new opportunities for climate change governance by providing novel and newly enhanced incentives. In particular, their usage helps to tie together and draw out those pieces of evidence of greatest relevance to different audiences, thereby helping policymakers and advocates to target messaging more effectively. Viewed thus, 'the narrative approach is not just another instrument to enable translation of scientific data and to add local forms of knowledge to the scientific one. Quite the contrary, the narrative approach challenges the exclusivity of the scientific definition of the climate problem and opens up new ways of dealing with a changing climate' (Krauß and Bremer 2020: 6). In seeking to achieve such a rebalancing, however, no single locality is sufficient. Rather, a genuinely useful articulation of climate change narratives requires the compilation and analysis of multiple interlinked and mutually influential narratives.

This paper constitutes an early effort to collate such a narrative set. Each of these narratives identified here provides a useful hook through which to engage different audiences on climate change and the need for sustainable and resilient transitions. Technology emerges as a crosscutting sub-theme highlighting opportunities to break down barriers, with a caveat that these must consider social dimensions of acceptance and uptake for sustainable transitions towards low-carbon homes. Similarly, social norms and peer pressure also emerge as a cross-cutting 
sub-theme in influencing positive engagement with low-carbon initiatives, with the perceived opinions of proximate others a dominant attitudinal influence. Considering each of these themes across the range of narratives that have been identified in this paper across the home, community, countryside and city themes provide opportunities for both transitions to lowcarbon future and building resilience to future climate impacts.

These early points of engagement constitute far from an overarching framework for exploring climate change narratives. In particular, more in-depth accounts of the role of memory, experience and place may be crucial to informing place-based climate change knowledge capable of articulation to shape narrative framing and messaging and in doing so effecting change in behaviours linked to climate change. Similarly a broader range of sites and places (e.g. the individual/body) could be considered that might speak to other distinctive behaviours, as could an exploration of the questions addressed in this paper applied across different places and generations. Above all, the examples outlined in this paper are therefore a call to add place-based understanding of climate change to the toolbox of climate change policy and analysis, seeking in doing so to tackle something of the biggest climate change challenges by beginning at the smallest scale.

Acknowledgements Thanks are extended to Grace Philip, to all interviewees and the anonymous reviewers.

Funding The authors received support from WWF-UK (Ref. 20110) and the UK Economic and Social Research Council through the Place-Based Climate Action Network (P-CAN) (Ref. ES/S008381/1).

Open Access This article is licensed under a Creative Commons Attribution 4.0 International License, which permits use, sharing, adaptation, distribution and reproduction in any medium or format, as long as you give appropriate credit to the original author(s) and the source, provide a link to the Creative Commons licence, and indicate if changes were made. The images or other third party material in this article are included in the article's Creative Commons licence, unless indicated otherwise in a credit line to the material. If material is not included in the article's Creative Commons licence and your intended use is not permitted by statutory regulation or exceeds the permitted use, you will need to obtain permission directly from the copyright holder. To view a copy of this licence, visit http://creativecommons.org/licenses/by/4.0/.

\section{References}

Aiken G (2012) Community transitions to low carbon futures in the transition towns network (TTN). Geogr Compass 6(2):89-99

Atkinson G, Bateman I, Mourato S (2012) Recent advances in the valuation of ecosystem services and biodiversity. Oxf Rev Econ Policy 28(1):22-47

Balta-Ozkan N et al (2013) Social barriers to the adoption of smart homes. Energy Policy 63:363-374

BEIS (2019) 2018 UK greenhouse gas emissions, provisional figures. London, UK

Boisselle LN (2016) Decolonizing science and science education in a postcolonial space. SAGE Open 6(1):1-11

Bremer S et al (2019) Toward a multi-faceted conception of co-production of climate services. Climate Serv 13: $42-50$

Buchanan K et al (2016) The British public's perception of the UK smart metering initiative: threats and opportunities. Energy Policy 91:87-97

Bushell S, Satre Buisson G, Workman M et al (2017) Strategic narratives in climate change: towards a unifying narrative to address the action gap on climate change. Energy Res Soc Sci 28:39-49

CCC (2015) Sectoral scenarios for the fifth carbon budget. Technical Report

CCC (2017) UK Climate Change Risk Assessment 2017. Synthesis report: priorities for the next five years. London

CCC (2019a) Reducing UK emissions - 2019 Progress report to parliament. London

CCC (2019b) Progress in preparing for climate change - 2019 Progress Report to Parliament. London 
Conway D et al (2019) The need for bottom-up assessments of climate risks and adaptation in climate-sensitive regions. Nat Clim Chang 9(7):503-511

Coulter L, Serrao-Neuman S, Coiacetto E (2019) Climate change adaptation narratives: linking climate knowledge and future thinking. Futures 111:57-70

Daniels S, Endfield G (2009) Narratives of climate change: introduction. J Hist Geogr 35(2):215-222

DECC (2011) The UK renewable energy roadmap

Demski C, Poortinga W, Pidgeon N (2014) Exploring public perceptions of energy security risks in the UK. Energy Policy 66:369-378

Devine-Wright P (2013) Think global, act local? The relevance of place attachments and place identities in a climate changed world. Glob Environ Chang 23(1):61-69

Devine-Wright P, Batel S (2017) My neighbourhood, my country or my planet? The influence of multiple place attachments and climate change concern on social acceptance of energy infrastructure. Glob Environ Chang 47:110-120

Devine-Wright P (2009) Rethinking NIMBYism: The role of place attachment and place identity in explaining place-protective action. Community and Applied Social Psychology. https://doi.org/10.1002/casp.1004

Downs A (1972) Up and down with ecology- the "issue-attention" cycle. Public Inter 28:38-50

Endfield G, Morris C (2012) Cultural spaces of climate. Clim Chang 113:1-4

Flottum K, Gjerstad O (2016) Narratives in climate change discourse. WIREs Clim Change 2017 8:e429. https:// doi.org/10.1002/wcc.429

Galway LP (2019) Perceptions of climate change in Thunder Bay, Ontario: towards a place based understanding. Local Environ 24(1):68-88

Geoghegan H, Leyson C (2012) On climate change and cultural geography: farming on the Lizard Peninsula, Cornwall, UK. Clim Chang 113:55-66

Guy S, Shove E (2000) A sociology of energy, buildings and the environment: constructing knowledge, designing practice. Routledge, London

Halperin A, Walton P (2018) The importance of place in communicating climate change to different facets of the American public. Weath Climate Soc 10(2):291-305

Hards S (2012) Tales of transformation: the potential of a narrative approach to pro-environmental practices. Geoforum 43(4):760-771

Heiskanen E et al (2010) Low-carbon communities as a context for individual behavioural change. Energy Policy $38: 7586-7595$

Hine DW et al (2014) Audience segmentation and climate communication: conceptual and methodological considerations. WIRES Clim Change 5(4):441-459

Howarth C (2017) Informing decision making on climate change and low carbon futures: framing narratives around the United Kingdom's fifth carbon budget. Energy Res Soc Sci 31:295-302

HPA (2012) Health effects of climate change in the UK 2012. Current evidence, recommendations and research gaps. Report by the Health Protection Agency

Hulme M (2015) Climate and its changes: a cultural appraisal. Geo: Geograp Environ 2(1):1-11

Jarnkvist K (2019) Intersectional perspectives of house owner narratives on climate risks. J Risk Res 1(1):1-14

Jones MD, McBeth MK, Shanahan EA (2014) Introducing the narrative policy framework. In: Jones MD et al (eds) The Science of Stories. Applications of the Narrative Policy Framework in Public Policy Analysis. Palgrave MacMillan, New York, pp 1-25

Krauß W, Bremer S (2020) The role of place-based narratives of change in climate risk governance. Clim Risk Manag 28:100221. https://doi.org/10.1016/j.crm.2020.100221

Lichtenstein S, Slovic P (eds) (2006) The construction of preference. Cambridge University Press, Cambridge

Lowe $\mathrm{T}$ et al (2006a) Does tomorrow ever come? Disaster narrative and public perceptions of climate change. Public Underst Sci 15(4):435-457

Lejano RP, Tavares-Reager J, Berkes F (2013) Climate and narrative: environmental knowledge in everyday life. Environ Sci Pol 31:61-70

Lockwood M (2011) Does the framing of climate policies make a difference to public support. Evidence from UK marginal constituencies. Clim Pol 11(4):1097-1112

Lowe T et al (2006b) Does tomorrow ever come? Disaster narrative and public perceptions of climate change. Public Underst Sci 15(4):435-457

Lyotard JF (1984) The postmodern condition: a report on knowledge. Manchester University Press, Manchester Menning N (2018) Narrating climate change as a rite of passage. Clim Chang 147(1-2):343-353

Middlemiss L, Parrish BD (2010) Building capacity for low carbon communities: the role of grassroots initiatives. Energy Policy 38:7559-7566

Moezzi M, Janda KB, Rotmann S (2017) Using stories, narratives, and storytelling in energy and climate change research. Energy Res Soc Sci 31:1-10 
Morris BS et al (2019) Stories vs. facts: triggering emotion and action-taking on climate change. Clim Chang 154:19-36

Mulugetta Y, Jackson T, van der Horst D (2010) Carbon reduction at community scale. Energy Policy 38:75417545

Myers TA et al (2012) A public health frame arouses hopeful emotions about climate change. Clim Chang 113(3):1105-1112

Nash $\mathrm{N}$ et al (2019) Local climate change cultures: climate-relevant discursive practices in three emerging economies. Clim Chang 163:63-82

Nisbet M (2009) Framing science: a new paradigm in public Engagment. In: Kahlor L, Stout P (eds) Communicating Science. Routledge, London

Olazabal M, Pascual U (2015) Urban low-carbon transitions: cognitive barriers and opportunities. J Clean Prod 109:336-346

Paschen J-A, Ison R (2014) Narrative research in climate change adaptation-exploring a complementary paradigm for research and governance. Res Policy 43(6):1083-1092

Poortinga W et al (2012) Individual-motivational factors in the acceptability of demand-side and supply-side measures to reduce carbon emissions. Energy Policy 48:812-819

Rogers A, Castree N, Kitchin R (2013) A dictionary of human geography. Oxford University Press, Oxford

Scannell L, Gifford R (2013) Personally relevant climate change: the role of place attachment and local versus global message framing in engagement. Environ Behav 45(1):60-85

Schweizer S, Davis S, Thompson JL (2013) Changing the conversation about climate change: a theoretical framework for place-based climate change engagement. Environ Commun 7(1):42-62

Smith J (2014) From truth to a war game of risk. In: Smith J, Tyszczuk R, Butler R (eds) Culture and Climate Change: Narratives. Culture and Climate Change. Shed, Cambridge, pp 15-24

van der Leeuw S (2019) The role of narratives in human-environmental relations: an essay on elaborating winwin solutions to climate change and sustainability. Clim Chang 160:509-519. https://doi.org/10.1007/ s10584-019-02403-y

Publisher's note Springer Nature remains neutral with regard to jurisdictional claims in published maps and institutional affiliations. 